\title{
Magnetic Core Studies at LBNL and LLNL
}

\author{
A. W. Molvik ${ }^{a}{ }^{*}$, A. Faltens ${ }^{b}$, L. Reginato ${ }^{b}$, M Blaszkiewicz $^{c}$, C. \\ Smithd, and R. Woode \\ a LLNL, Livermore, CA 94550, USA \\ b LBNL, Berkeley, CA 94720, USA \\ c Westinghouse, STC, 1310 Beulah Road, Pittsburgh, PA 15235-5098, USA \\ d Nonvolatile Electronics, Inc., 11409 Valley View Road, Eden Prairie, MN 55433-3617 \\ e National Magnetics, Inc., Adelanto, CA 92301
}

\begin{abstract}
The objective of this work is to minimize the cost of the materials and maximize the performance of magnetic cores, a major cost component of a Heavy-Ion-Fusion, HIF, induction accelerator driver. This includes selection of the alloy for cost and performance, and maximizing the performance of each alloy evaluated. The two major performance parameters are the magnetic flux swing and the energy loss. The volt seconds of the cores, obtained from the flux swing with Faraday's Law, determines the beam energy and duration. Core losses from forming domains and moving their boundaries are a major factor in determining the efficiency of an induction accelerator.

PACS numbers: 75.50Kj, 75.50.Bb, 75.60.Ej, 77.22.Jp

* Corresponding author. Tel.: 510422 9817; fax: 510423 2664; e-mail: molvik1@1lnl.gov.
\end{abstract}

\section{Introduction}

A $5 \mathrm{MJ}$ induction linac driver for HIF needs $\sim 3 \infty 10^{7} \mathrm{~kg}$ of magnetic material.[1] To achieve a cost goal of $<10^{9}$ \$US for a driver, core costs must be much less than the current $\sim 100 \$ / \mathrm{kg}$ in small quantities. A nearer term experiment being evaluated, needs $\sim 2 \infty 10^{6} \mathrm{~kg}$ to deliver $25 \mathrm{~kJ}$ to a target.[2] Here also, cost reductions are important for achieving a marketable design. A recirculating induction accelerator passes the beam through each core many times, reducing the mass of cores required.[3] For a recirculator, core optimization emphasizes minimizing core energy losses more than minimizing initial cost.

As have previous studies of magnetic materials, we have focused on amorphous alloys of steel that can be formed into ribbons of $15-25 \mu \mathrm{m}$ thickness, at a much lower cost than by rolling. [4] The performance is significantly enhanced by magnetic annealing[5] where the ribbon is heated to $\sim 360 \infty \mathrm{C}$ in an inert atmosphere while a magnetic field is applied parallel to the ribbon. If the material is annealed, prior to 
winding into a core, it loses $24 \%$ or more of its flux swing capability. The alloy embrittles during the anneal, and is much more difficult to wind after anneal.

Annealing after winding is advantageous both to gain the full flux swing, and to wind while the material is still ductile. A complication arises in short pulse applications where a turn-to-turn voltage of up to $100 \mathrm{~V}$ is induced. Insulation capable of withstanding this voltage, to block interlaminar eddy currents, is required for high performance.[6] The characteristics that make an insulator suitable for anneal-after-wind are:

- Hold voltage of 0.1-100 V per layer. Near the injection end of a driver accelerator, pulses are longer (10-100 $\mu \mathrm{s})$ so the voltage is lower for similar volt-second cores. At the high energy end of a driver, pulses are as short as 100-200 ns, and the voltage is correspondingly higher. Occasional shorts can be permitted with little effect on performance, but if multiple shorts are aligned to provide low-impedance eddycurrent paths, performance degrades.

- Withstand annealing temperatures near $360 \infty \mathrm{C}$ for about two hours and retain, or regain, the other desired properties after cool down.

- Apply minimal mechanical stress to the alloy. Matching coefficients of thermal expansion would be ideal. Alternatively, the insulation can be made so thin that it can't apply stress, as long as it still holds sufficient voltage after winding and annealing.

- Thin, $<2-3 \mu \mathrm{m}$, maintains the packing fraction, $\mathrm{PF}$, near $80 \%$. The PF is defined as the ratio of the volume of alloy to the total winding volume. This criterion is frequently less stringent than the minimal stress requirement.

- Coating the alloy is preferable to a co-wound ribbon insulator for simpler winding, thinner insulation and higher PF, and the elimination of insulation overlap at the sides of the core, which impedes cooling and hinders annealing a core on its side.

- Potential of low cost restricts the cost of the insulator material, the cost of applying it, and of drying, curing and winding it. Some materials, such as polyimide and Parylene-N are apparently costly at nearly $1000 \$ / \mathrm{kg}$, but could be acceptable if applied in thin-enough coatings (5-25 nm). Vacuum vapor deposition (Parylene-N) will be more costly than dipping the metal ribbon in a dilute coating solution (e.g., polyimide, sodium silicate). Finally, we prefer a rapid cure at near room temperature. - Lifetime, the order of 30 years, avoids the need for replacing components during the life of a driver. At the end of life, the metal and insulator should be easily separated, to allow recycling both materials.

The leading candidates among amorphous alloys include Metglas alloy $2605 \mathrm{CO}$ which provides the largest flux swing, 3.5T, but the energy loss is high also, and the cobalt content increases the cost.[4,7] Cobalt costs have varied over a factor of 3 , and currently run near $50 \$ / \mathrm{kg}$. [8] 2605CO retains more ductility after annealing, and has been the material of choice for wind-after-anneal.[9] A cobalt-free alloy, 2605SC, provides nearly as high a flux swing, $3.1 \mathrm{~T},[4,7]$ but embrittles during anneal. Its lower losses and potentially much lower cost have made it the first choice for HIF applications. SA1 is a variant of $2605 \mathrm{SC}$, optimized for low cost and $60 \mathrm{~Hz}$ operation. It is currently priced at $20 \$ / \mathrm{kg}$ in $100 \mathrm{~kg}$ lots and below $4 \$ / \mathrm{kg}$ in large quantities. An informal quotation from Allied Signal, that manufactures the amorphous alloys mentioned in this 
paragraph, indicates that demand could also drive the cost of $2605 \mathrm{SC}$ to $\leq 5 \$ / \mathrm{kg}$ in $10^{5}$ $\mathrm{kg}$ lots. We are concentrating our efforts on 2605SC and SA1.

\section{Anneal after wind feasibility tests}

For insulation, we chose $18 \mu \mathrm{m}$ thick mica paper as a co-wound insulator.[5] Its thickness and cost violate our requirements, but it appears suitable for test purposes, to evaluate anneal-after-wind. The packing fractions were between 20-30\% with mica paper, and would have reached $40 \%$ if densely packed. We wound 500 turns of $16.7 \mu \mathrm{m}$ thick 2605 SC on Zircar SALI or AL-30 ceramic cylinders of $12.5 \mathrm{~cm}$ OD. The ceramic was chosen because its coefficient of thermal expansion of $5.0 \infty 10^{-6} / \infty \mathrm{C}$ is a close match to $2605 \mathrm{SC}$ at $5.9 \infty 10^{-6}$ or SA1 $2-7 \infty 10^{-6} / \infty \mathrm{C}$ respectively. The SA1 cores tested here were coated with magnesium methylate.[10]

To measure the properties of the cores, we discharge a $1 \mu \mathrm{fd}$ capacitor bank through a thyratron switch into 1 to 20 primary turns wrapped around the minor cross section of the toroidal cores. A reset current pulse, in the reverse direction, immediately precedes the main pulse. For this work, we allow the reset current to decay to zero before the main pulse, leaving the core at the reversed remnant field, $-\mathrm{B}_{\mathrm{r}}$. The current, I, through the primary is measured with a current transformer. The voltage, $\mathrm{V}$, across a 1-turn secondary is measured with a $\infty 1000$ high-voltage probe. The data are collected with a $100 \mathrm{MS} / \mathrm{s}$ digital oscilloscope, then acquired and analyzed with computers. The magnetization rate is $\mathrm{dB} / \mathrm{dt}=\mathrm{V} / \mathrm{A}_{\mathrm{c}}$ where $\mathrm{A}_{\mathrm{c}}$ is the net cross-sectional area of the amorphous metal in the core, determined by weight, or equivalently from the product of $\mathrm{PF}$ times the geometrical area. The flux swing $\mathrm{dB}$ is given by

$$
\mathrm{dB}=\Re \mathrm{Vdt} / \mathrm{A}_{\mathrm{c}}
$$

where $\mathrm{dt}$ is the digitizing interval between points. Equation (a) is computed for every data point in the shot. We then select points $\mathrm{a}_{0.5}, \mathrm{a}_{1.5}, \mathrm{a}_{2.5}, \ldots$ with the desired $\mathrm{dB}$ (e.g., $0.5,1.5,2.5, \ldots$ Tesla) and compute the average $\mathrm{dB} / \mathrm{dt}$ and losses to those points. The loss $\mathrm{U}$ is

$$
\mathrm{U}(\mathrm{J})=\mathfrak{R} \mathrm{V} \text { I dt }
$$

and

$$
\mathrm{u}(\mathrm{J} / \mathrm{m} 3)=\mathrm{U}(\mathrm{J}) / \mathrm{V}_{\mathrm{c}}
$$

where $\mathrm{V}_{\mathrm{c}}$ is the volume of amorphous metal, determined by weight and the manufacturer's published density, or equivalently, $\mathrm{V}_{\mathrm{c}}$ is the product of PF times the geometrical volume. 
Our procedure is to wind a core, make measurements over the maximum range of $\mathrm{dB} / \mathrm{dt}$, limited by the $10 \mathrm{kV}$ limit of the pulser at the upper end, and by insufficient charge in the capacitors to saturate the core at the lower end. After the as-cast core is characterized, we anneal at $365 \infty \mathrm{C}$ for 2 hours in a nitrogen atmosphere.[5] We then repeat the magnetic measurements. The results with $5 \mathrm{~cm}$ wide cores wound with $5 \mathrm{lbs}$. tension, which achieved PF $30 \%$ showed no improvement from the annealing, Fig 1. We tried lower winding tension, finding that $0.18-0.5 \mathrm{lbs}$ produced better performing cores, but with a lower PF $20 \%$, a pillowy feel, and a poorer appearance. The results reported in this paper are from this group of cores. Three cores shown in Fig. 1 came from different batches of 2605SC. Further work will test whether the anneal time and temperature are optimized. A new nitrogen convection oven is being installed to provide a lower oxygen content and faster removal of volatiles off the core, which may also have some effect on core performance.

The loss versus the magnetization rate is plotted in Fig. 2(a) for flux swings of 0.5 , 2.0, and 2.5 $\mathrm{T}$ for annealed and $0.5 \mathrm{~T}$ for as-cast 2605SC. Interestingly, at $0.5 \mathrm{~T}$, the losses are lower for as-cast than for annealed, but at higher $\mathrm{dB}$, the reverse is true. Faltens has devised 1 and 2 term criteria to compare different magnetic materials,[11]

$$
\begin{aligned}
& \mathrm{u}(\mathrm{J} / \mathrm{m} 3)=850(\mathrm{~dB} / 2.5 \mathrm{~T})^{2}(1 \mu \mathrm{s} / \tau)(\mathrm{t} / 25.4 \mu \mathrm{m})^{1-2} \\
& \text { and } \\
& \mathrm{u}(\mathrm{J} / \mathrm{m} 3)=100(\mathrm{~dB} / 2.5 \mathrm{~T})\left(\tau^{0}\right)(\mathrm{t} / 25.4 \mu \mathrm{m})+750(\mathrm{~dB} / 2.5 \mathrm{~T})^{2}(1 \mu \mathrm{s} / \tau)(\mathrm{t} / 25.4 \mu \mathrm{m})^{1-2}
\end{aligned}
$$

where $\tau(\mu \mathrm{s})$ is the time, and $\mathrm{t}(\mu \mathrm{m})$ is the thickness of the ribbon with an exponent of 1 or 2 (an exponent of 1 is used in Fig. 2). Both criteria fit well at high excitation rates, near $10^{7} \mathrm{~T} / \mathrm{s}$, but the 2-term criterion fits better at lower excitation rates also, and is shown in Fig. 2(a).

Similar measurement are shown for SA1 in Fig. 2(b). Here the losses for as-cast are significantly greater than for annealed with all flux swings. The 2-term criterion tracks the measurements well, but lies below them. The difference is greater at $\mathrm{dB}=3 \mathrm{~T}$ which is near saturation where losses are observed to increase more rapidly with $\mathrm{dB}$. The $3 \mathrm{~T}$ operation is near previously reported maximum $\mathrm{dB}$, and the $\mathrm{SA} 1$ processing is considered optimized.

We plot performance data for annealed 2605SC and SA1 together in Fig. 2(c). The losses are similar with $10-20 \%$ greater loss for SA1. This is too close to be significant without more samples to provide statistics, and without determining that the 2605SC anneal is optimized. Irrespective of which alloy may ultimately prove superior, it is clear that annealed-after-wind SA1 performs near the levels expected from 2605SC over a wide range of flux swings, and at current prices looks like a good choice for near-term small accelerators.

Parylene was tested as a potential insulating coating that could withstand $365 \mathrm{C}$. (using the Parylene-N variant that melts at $410 \infty \mathrm{C}$ ). Coatings with average thicknesses of 25,50 , and $200 \mathrm{~nm}$ were applied to $0.4 \mathrm{~m}$ lengths of $0.05 \mathrm{~m}$ wide $2605 \mathrm{SC}$. The thickness 
was determined from the weight gain of an adjacent glass slide, but is known to vary by $\sim 15 \%$. A $2.8 \mathrm{~g}$ weight with a cylindrical base of $1 \mathrm{~cm}^{2}$ area, suspended by a $150 \mu \mathrm{m}$ diameter wire was carefully lowered to the sample with no potential difference. After it was in place, the voltage on the weight was applied at $10 \mathrm{~V}$ and slowly raised. We recorded the highest voltage at which breakdown did not occur in Fig. 3. The results scale even more slowly than the $\mathrm{V} \propto \mathrm{t}^{0.5}$ line that characterizes voltage breakdown in the vicinity of $\mathrm{t}=0.125-5.0 \mathrm{~mm}$.[12] At $25 \mathrm{~nm}$ which is about 80 atomic layers thick, $100 \mathrm{~V}$ corresponds to $1.2 \mathrm{~V} /$ (atomic layer). This approaches the few $\mathrm{eV}$ bonding energy between atoms, and is probably near the ultimate limit.

The voltage holding at $25 \mathrm{~nm}$ appears adequate if the coating is not damaged during wind and anneal. In such thin layers, the cost of the material becomes acceptable, however vacuum vapor deposition is a relatively costly method of coating. We expect to concentrate our efforts on other coatings, returning to Parylene only if other possibilities are found to be unsuitable.

\section{Conclusions}

- The least expensive alloy, SA1, is closely competitive with the performance of 2605SC, and offers significant savings on near term experiments.

- Anneal-after-wind has demonstrated its promise with SA1, achieving near $100 \%$ of the ideal flux swing. Present results with 2605 SC exceed $90 \%$ of the ideal, which is better than the maximum of $76 \%$ ideal achieved with wind after anneal.[5].

- Further insulator coating development is needed to find materials and develop methods to meet the cost and performance requirements.

- Further testing is required to determine whether $2605 \mathrm{SC}$ offers sufficient advantage to justify development of a continuous casting line and a suitable coating.

- Finally, assembled cores costing near $5 \$ / \mathrm{kg}$ will require improvements in all areas of core manufacture including casting, coating, winding, annealing, possible potting, and transporting to the destination accelerator.

Helpful suggestions from J. M. Moller for automating data analysis are gratefully acknowledged. The cores were capably constructed by M. C. Fowler and C. S. Firpo, and annealed by R. N. Accardo. J. L. Stoker and R. R. Hipple ably supported the testing. This work was performed under the auspices of the U.S. Department of Energy under contract No. W-7405-ENG-48 (LLNL) and DE-AC03-76SF00098 (LBNL). 


\section{References}

[1] Wayne Meier, Roger O. Bangerter, and Andy Faltens, "An Integrated Systems Model for Heavy Ion Drivers," This conference.

[2] Faltens, "HTE Update," Unpublished (1997).

[3] J. J. Barnard, et al., Phys. Fluids B 5 (1993) 2698.

[4] Carl H. Smith, J. Appl. Phys. 67 (1990) 5556.

[5] Carl H. Smith, Bob. N. Turman, and Henry C. Harjes, IEEE Trans. on Electron Devices 38 (1991) 750 .

[6] D. M. Nathasingh, C. H. Smith and A. Datta, IEEE Transactions on Magnetics 20 (1984) 1332.

[7] A. Faltens, S. S. Rosenblum, C. H. Smith, J. Appl. Phys. 57 (1985) 3508.

[8] SRI Consulting, cbrd-webmaster@sric.sri.com, Feb. 7, 1997.

[9] C. W. Huddle, D. L. Johnson, G. G. Denison, and T. L. Franklin, "Testing of the inductor cores for HERMES III," in IEEE Conf. Rec. 16th Pulsed Power Conf. (Arlington, VA, June, 1987) 240.

[10] Richard H. Wood, "Making a Workable Core," Internat'1 Magnetic Pulse Compression Workshop, LLNL report CONF-900280, Vol. 2, (1991) 53.

[11] A. Faltens, private communication (1997).

[12] Edward R. Salmon, IEEE Electrical Insulation Magazine 5 (Jan./Feb., 1989) 36. 


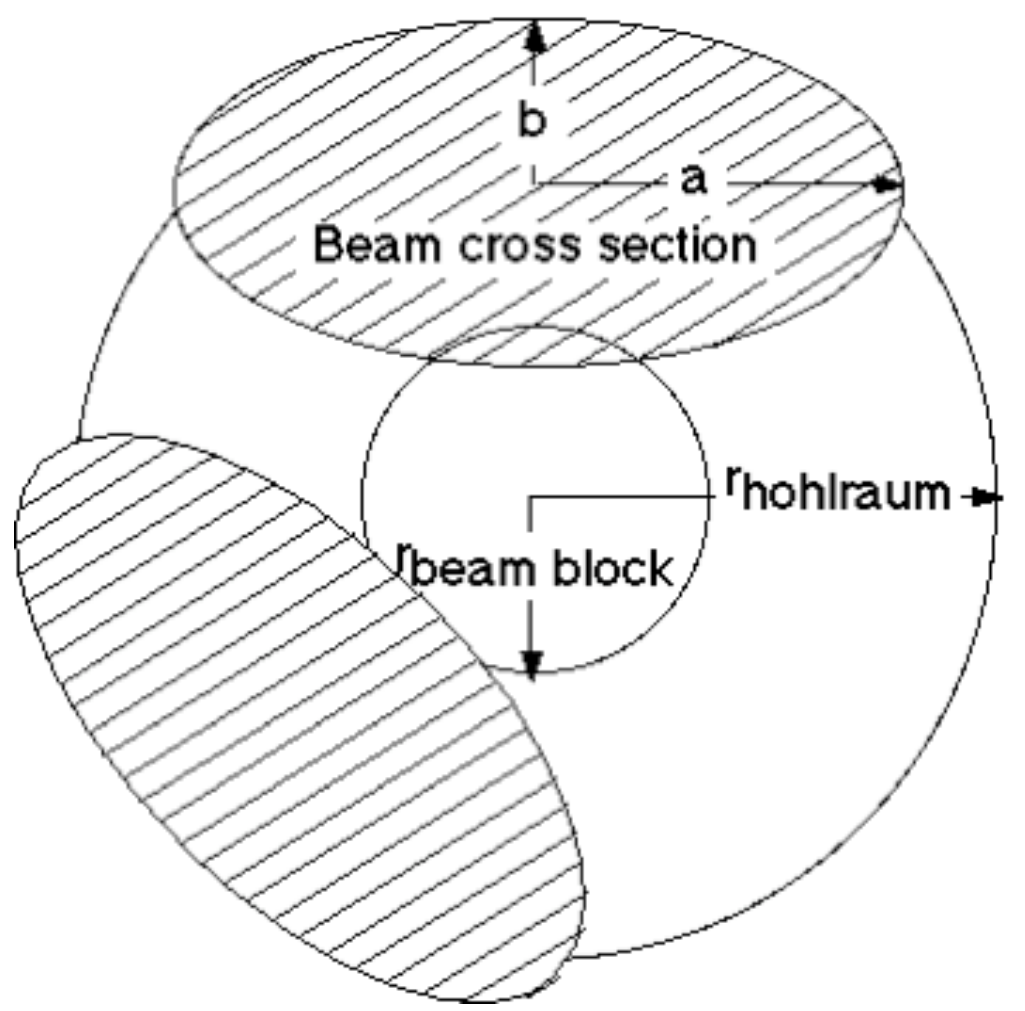

Fig. 1. The flux swing of 2605SC increases with annealing only at low winding tension. The flux swing is integrated until core losses reach $500 \mathrm{~J} / \mathrm{m} 3$. Mica paper, $18 \mu \mathrm{m}$ thick, provides turn-to-turn insulation.

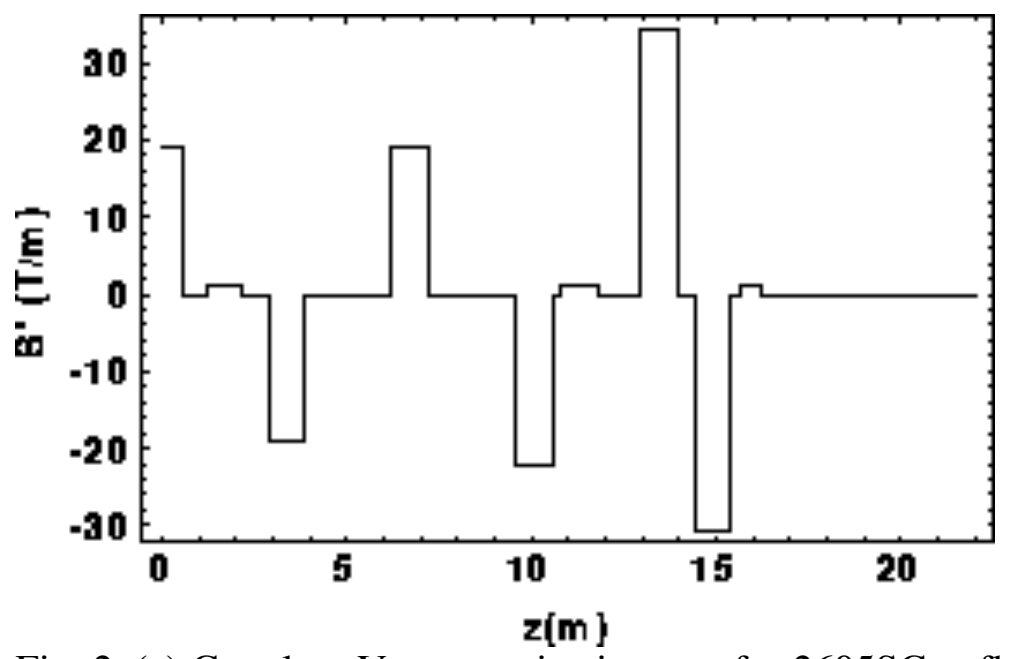

Fig. 2. (a) Core loss Vs magnetization rate for $2605 \mathrm{SC}$ at flux swings of $0.5,2.0$, and 2.5 $\mathrm{T}$, annealed after winding, and $0.5 \mathrm{~T}$, as cast, compared with 2-term criterion. 


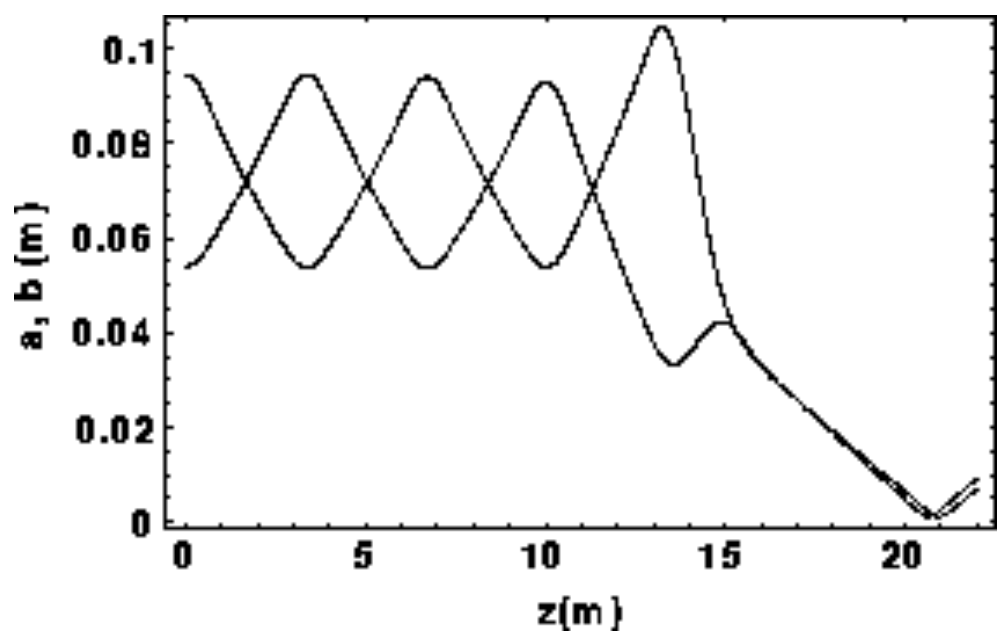

(b) Same for SA1 at flux swings of 0.5, 2.0, and 3.0 T, annealed after winding and 0.5 and $2 \mathrm{~T}$, as cast.

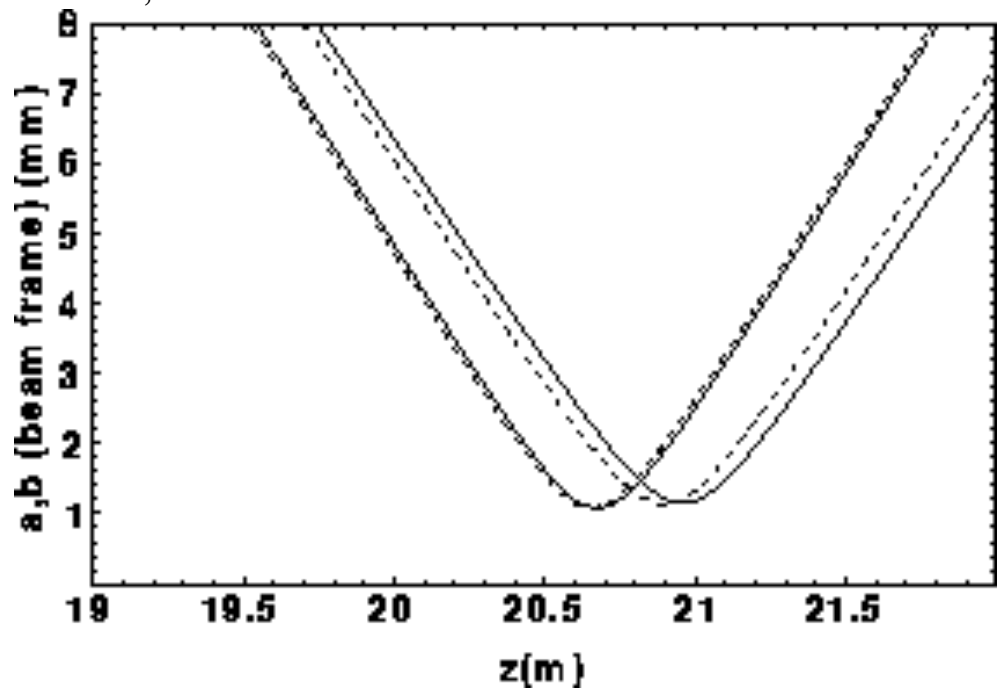

(c) Comparison of $2605 \mathrm{SC}$ and SA1 at $2.5 \mathrm{~T}$, and at $0.5 \mathrm{~T}$ flux swing, annealed after winding.

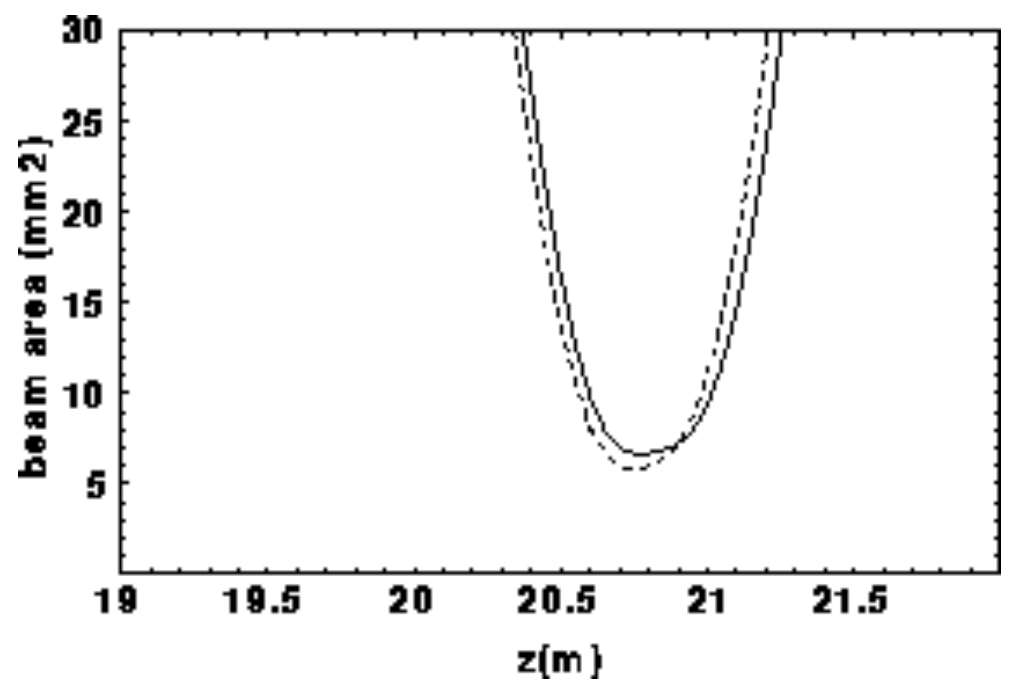




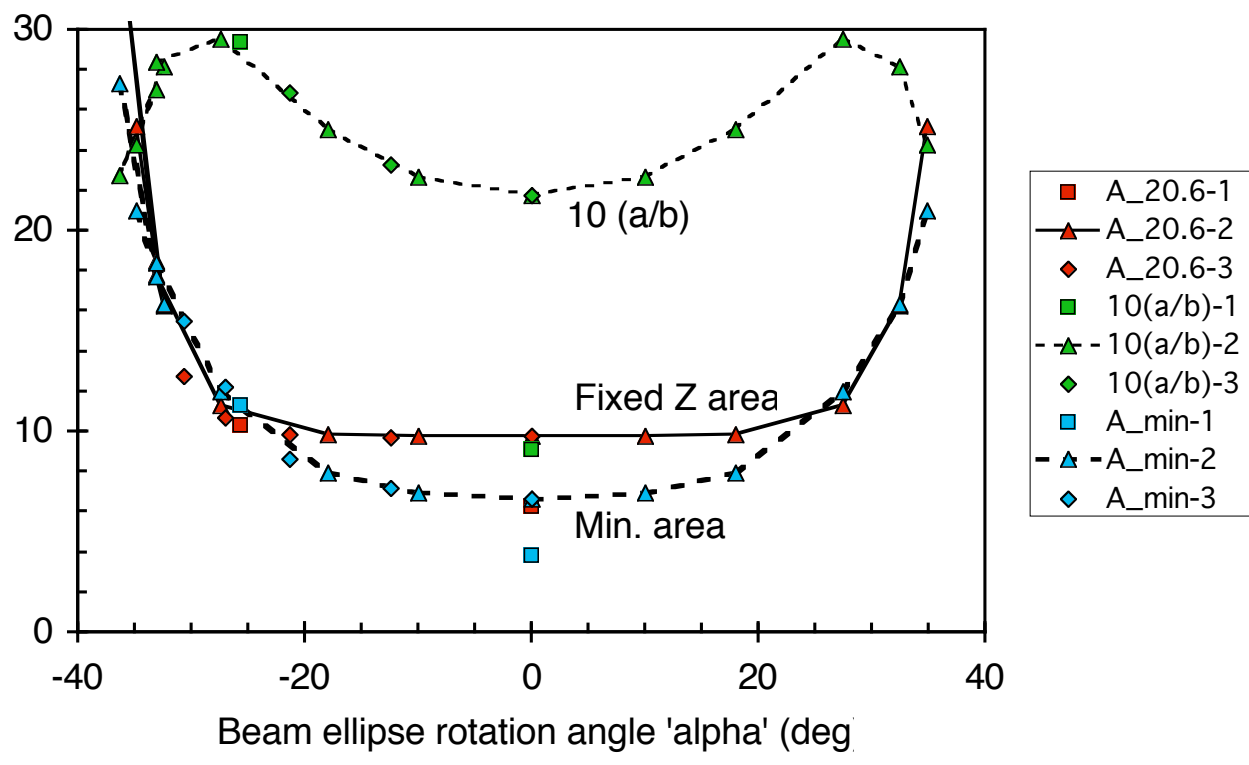

Fig. 3. Parylene-N coatings withstand $\sim 100 \mathrm{~V}$, before winding or annealing, with

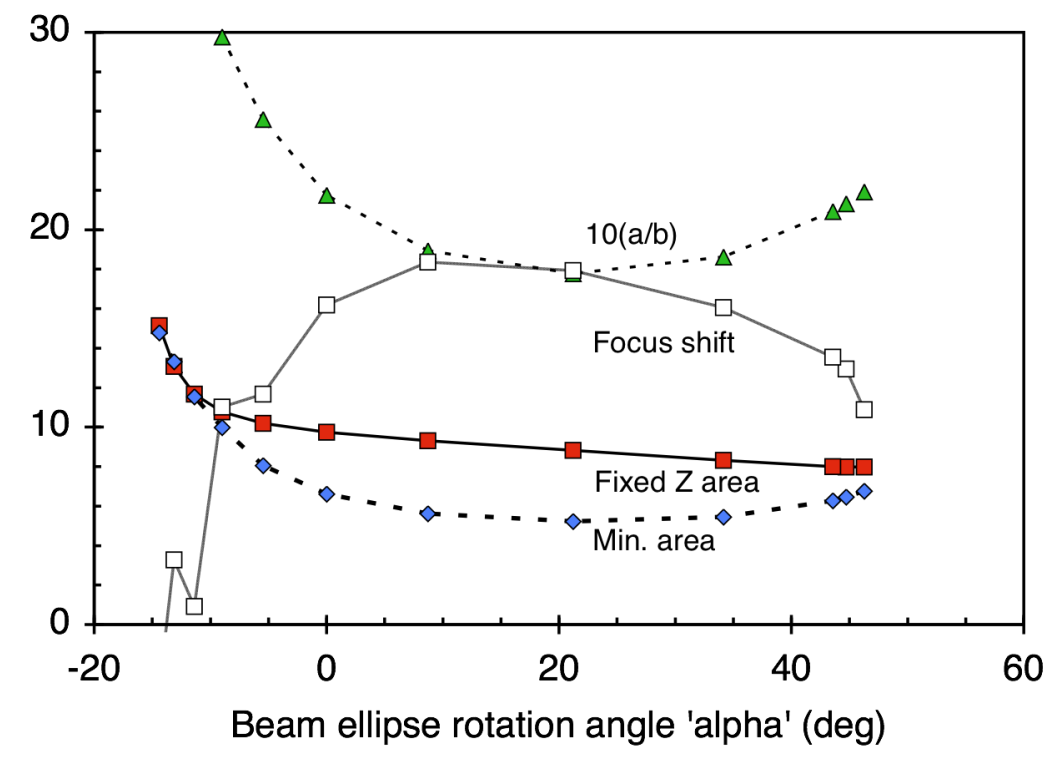

thicknesses of 25-200 nm.

Figure 4 